\title{
Utility of echocardiography in assessment of pulmonary hypertension secondary to COPD
}

\author{
M.A. Higham*, D. Dawson", J. Joshi", P. Nihoyannopoulos", N.W. Morrell*
}

Utility of echocardiography in assessment of pulmonary hypertension secondary to COPD. M.A. Higham, D. Dawson, J. Joshi, P. Nihoyannopoulos, N.W. Morrell. (C) ERS Journals Ltd 2001.

ABSTRACT: Studies have confirmed the close correlation of echocardiographically estimated pulmonary arterial pressure with invasive measurements in patients with chronic obstructive pulmonary disease (COPD), but there are few data on utility of echocardiographic measurement in assessing pulmonary arterial hypertension $(\mathrm{PH})$ in COPD and correlation with pulmonary function tests.

Presence or absence of tricuspid regurgitation (TR) was determined by Doppler echocardiography in 73 consecutive COPD patients attending a hospital outpatient clinic. Transtricuspid pressure gradient (TTPG) was calculated. PH was defined as TTPG $\geqslant 30 \mathrm{mmHg}$. Patients also underwent spirometry, forced expiratory volume in one second (FEV1), single breath gas transfer (carbon monoxide transfer coefficient; (KCO) and carbon monoxide diffusing capacity of the lung; $D \mathrm{~L}, \mathrm{CO}$ ) and arterial blood gas measurement.

Measurable TR was observed in $56 / 73$ patients $(77 \%)$. There were no differences between the group in which TR was observed compared to that in which it was absent, with regard to age, smoking history nor pulmonary function variables. PH was seen in $31 / 56$ cases $(55 \%)$, with good reproducibility. There were statistically significant correlations of TTPG with FEV1 $(r=-0.26, p=0.05), K C O \quad(r=-0.31, p=0.04)$ and $D_{\mathrm{L}, \mathrm{CO}}(\mathrm{r}=-\mathbf{0 . 4 2}, \mathrm{p}=0.006)$ expressed as \% pred. Stepwise regression analysis showed that age and $K \mathrm{CO}$ combined provide a multivariate model for prediction of TTPG.

It is concluded the presence and degree of pulmonary arterial hypertension is readily and reliably determined by echocardiography in the majority of chronic obstructive pulmonary disease patients. Pulmonary arterial hypertension is common in severe chronic obstructive pulmonary disease and transtricuspid pressure gradient correlates with spirometry and indices of gas transfer, similar to previous invasive studies. In view of the adverse effects of pulmonary arterial hypertension on morbidity and mortality routine echocardiography in patients with severe chronic obstructive pulmonary disease may be warranted.

Eur Respir J 2001; 17: 350-355.
*Clinical Pharmacology and ${ }^{\#}$ Clinical Cardiology, Imperial College School of Medicine, London, UK.

Correspondence: N.W. Morrell, Section on Clinical Pharmacology, Imperial College School of Medicine, Hammersmith Hospital, Du Cane Road, London, W12 0NN, UK Fax: +442087439733.

Keywords: Chronic obstructive pulmonary disease

Doppler echocardiography secondary pulmonary hypertension

Received: August 82000

Accepted after revision September 25 2000

This study was funded in part by a grant-in-aid from Merck Sharp \& Dohme Ltd.
Chronic obstructive pulmonary disease (COPD) due to smoking tobacco is the major cause of respiratory insufficiency in industrialized countries, accounting for $6.4 \%$ of all deaths in British males and $3.9 \%$ of deaths in British females [1]. It results in $\sim 450,000$ hospitalizations per year in the USA [2] and is the fourth leading cause of mortality in the USA $(109,000$ deaths per annum, equivalent to $4.7 \%$ of all deaths) [3]. The disease is characterized by slowly progressive airflow obstruction, resulting in dyspnoea and exercise limitation, and pulmonary arterial hypertension $(\mathrm{PH})$ is its major cardiovascular complication. Although the true prevalence of $\mathrm{PH}$ is unknown, an elevation of pulmonary arterial pressure is reported to occur in $5-40 \%$ of patients in series of selected individuals with severe COPD undergoing right heart catheterization [4]. The magnitude of $\mathrm{PH}$ measured invasively correlates with indices of airflow obstruction and gas exchange, but the relationship is weak [5]. The degree of $\mathrm{PH}$ secondary to
COPD is generally considered mild (e.g. mean pulmonary arterial pressure in the region of $25 \mathrm{mmHg}$ ) and slowly progressive $\left(\sim 1 \mathrm{mmHg} \cdot \mathrm{yr}^{-1}\right)$ [6], but dramatic elevations of pulmonary arterial pressure are observed on exercise, during nocturnal desaturations and during acute exacerbations [7]. Pulmonary arterial pressure is an important prognostic indicator in COPD, which has been underlined by a recent study demonstrating that $\mathrm{PH}$ predicts the number of exacerbations and length of hospital stay in COPD patients [8]. Large studies have confirmed that elevated pulmonary arterial pressure is a predictor of mortality independent of airflow limitation in COPD [9, 10], 5-yr mortality being particularly high at mean pulmonary arterial pressures in excess of $30 \mathrm{mmHg}$, increasing to $100 \%$ at mean pressures $>50 \mathrm{mmHg}$ [4].

Cardiac catheterization remains the "gold standard" for the measurement of pulmonary arterial pressures, $\mathrm{PH}$ at catheterization being defined as resting mean 
pulmonary arterial pressure $\geqslant 20 \mathrm{mmHg}$ or resting systolic pulmonary arterial pressure $\geqslant 30 \mathrm{mmHg}$ [11]. However, there are significant risks [12] and cost issues associated with the procedure and, in any case, due to the high prevalence of COPD it would not be feasible to perform cardiac catheterization on every patient with moderate to severe disease. Moreover, the technique does not lend itself well to the repeated and temporally close measurements required in clinical trials of interventions in secondary $\mathrm{PH}$. Thus, a reliable, reproducible, noninvasive technique for assessment of pulmonary arterial pressure would clearly be of great clinical and research value.

SKJAERPE and HATLE [13] were the first to report that the pressure gradient across a regurgitant tricuspid valve can be estimated from the peak velocity of the systolic transtricuspid jet measured using Doppler echocardiography. Subsequent studies of the use of Doppler echocardiography in assessing $\mathrm{PH}$ in patients with COPD have generally concentrated on evaluating the accuracy of the technique, mainly by correlating echocardiographically derived measurements with pressures obtained at cardiac catheterization. Large studies have confirmed that echocardiographically derived estimates correlate closely with pressures measured by catheter $(r>0.7)[14,15]$, although in a mixed group of COPD patients both with and without evidence of elevated right ventricular systolic pressures the investigators found their Doppler measurements to be adequate for estimation of tricuspid regurgitant velocity in only $30 \%$ of patients [15].

Given the previously demonstrated accuracy of estimation of pulmonary arterial pressures by measurement of the tricuspid regurgitant jet and recent advances in echocardiography, a study was designed in a consecutive unselected series of hospital outpatients with COPD in order to determine the utility of continuous wave Doppler echocardiography in the assessment of presence and severity of $\mathrm{PH}$ in such patients.

\section{Methods}

\section{Subjects}

The study was approved by the Research Ethics Committee of Imperial College School of Medicine, Hammersmith, Queen Charlotte's \& Chelsea and Acton Hospitals. All patients gave their written informed consent to participate in the study.

The patient group consisted of an unselected consecutive group of smokers and exsmokers recruited from a single Respiratory outpatient clinic at the Hammersmith Hospital. All had irreversible chronic airflow limitation and a diagnosis of COPD made according to British Thoracic Society guidelines [16]. Patients had not suffered an exacerbation of COPD for at least one month prior to echocardiography.

Healthy volunteers were recruited from Medical School staff to participate in an assessment of the sensitivity of Doppler echocardiography to acute changes in pulmonary arterial pressures.

\section{Pulmonary function tests and echocardiography}

Pulmonary function tests were performed by experienced specialist lung function technicians. Patients were seated. Spirometric measurements (forced expiratory volume in one second (FEV1), vital capacity (VC)) were made using a dry wedge bellows spirometer (Vitalograph Ltd, Buckingham, UK) and single breath carbon monoxide gas transfer (carbon monoxide transfer coefficient $(\mathrm{KCO})$, carbon monoxide diffusing capacity at the lung $(D \mathrm{~L}, \mathrm{CO}))$ measurements were made using a Morgan Benchmark system (Rainham, Kent, UK). Pulmonary function reference values were calculated according to the European Respiratory Society's statement on standardized lung function testing [17]. Arterial blood gas samples were obtained if clinically indicated and arterial oxygen and carbon dioxide tension $\left(\mathrm{Pa}, \mathrm{O}_{2}\right.$ and $\left.\mathrm{Pa}, \mathrm{CO}_{2}\right)$ measurements made using an ABL5 blood gas analyser (Radiometer, Copenhagen, Denmark).

Doppler echocardiographic investigations were performed by experienced cardiac technicians using a Toshiba Powervision model SSA380 ultrasound scanner and a multifrequency probe with a range of 2.5-3.7 MHz (Toshiba Medical Systems, Crawley, West Sussex, UK). Presence and location of systolic tricuspid regurgitation (TR) was verified by colour Doppler echocardiography. All patients were semisupine and continuous wave Doppler recordings of maximal velocity were obtained from apical, lower left parasternal and subcostal transducer positions. Recordings were considered optimal after systematic examination of each transducer position to locate the signal of highest audible frequency, maximal velocity and most clearly definable spectral envelope. The peak regurgitant velocity of three waveforms was measured where a clearly defined spectral envelope was visible. Mean maximum TR velocity was recorded in $\mathrm{m} \cdot \mathrm{s}^{-1}$ and inserted into the modified Bernoulli equation $\left(4 \mathrm{~V}^{2}\right)$, thus calculating the transtricuspid pressure gradient (TTPG) in mmHg [18]. PH was defined as TTPG $\geqslant 30 \mathrm{mmHg}$ [11].

In order to assess reproducibility of TTPG estimation a selected group of 20 patients with echocardiographic evidence of $\mathrm{PH}$ underwent repeat echocardiography within 3 months of their initial assessment, with the sonographer naive to the previous TR measurements.

Verification that continuous mode Doppler echocardiography is sensitive to changes in TTPG was performed. Measurements of mean TR velocity were made as described above in five normal volunteers breathing room air and were then immediately repeated after $10 \mathrm{~min}$ hypoxia breathing $10 \%$ oxygen via a mouthpiece from a Douglas bag. Arterial oxygen saturation and electrocardiograph were monitored throughout.

\section{Data analysis}

Reproducibility of TR measurement was assessed by Bland-Altman analysis [19]. Changes in TTPG under conditions of hypoxia were analysed using a one-tailed paired t-test. Differences in age, smoking history and 
lung function indices between the group in which TR was measurable against that in which there was no signal were compared using unpaired two-tailed t-tests. Correlations of TTPG with age, smoking history and indices of pulmonary function were tested for normality and analysed using the Pearson test for parametric data. Stepwise regression analysis was employed to determine whether a multivariate model was a better predictor of TTPG than individual variables (age, FEV1, KCO or smoking history) alone. A cut-off of $p=0.1$ was used for removing variables and $p=0.05$ for adding variables.

\section{Results}

Seventy-three patients were recruited into the study. Demographics, smoking history and pulmonary function are presented in table 1 . There were no significant differences with regard to age, smoking history nor pulmonary function variables between the group in which a transtricuspid regurgitant jet was measurable compared with that in which there was no signal.

Based upon British Thoracic Society guidelines [15], patients were classified as having mild (FEV $1 \geqslant 60 \%$ pred, $\mathrm{n}=12$ ), moderate (FEV1 $40-59 \%$ pred, $\mathrm{n}=19$ ) or severe (FEV $1<40 \%$ pred, $\mathrm{n}=42$ ) COPD. TR was observed in 56 patients (77\%). Mean(SD) TTPG for the entire group in which TR could be measured was 33.5 (10.5) $\mathrm{mmHg}$. PH was seen in $31 / 56$ cases $(57 \%)$. The frequencies of $\mathrm{PH}$ in mild, moderate and severe COPD were $25 \%, 43 \%$ and $68 \%$ respectively.

The reproducibility of TR measurement was assessed in 20 patients in whom echocardiography had previously revealed a TTPG $\geqslant 30 \mathrm{mmHg}$. BlandAltman analysis demonstrated that the technique was

Table 1.-Demographics of chronic obstructive pulmonary disease patients

\begin{tabular}{lccc}
\hline Parameters & All patients & $\mathrm{TR}+$ & $\mathrm{TR}-$ \\
\hline Subjects n & 73 & 56 & 17 \\
Age yr & $66.7(8.1)$ & $65.9(8.5)$ & $69.3(6.3)$ \\
Smoking history & & & \\
\multicolumn{1}{c}{ pack yrs } & $49.0(22.5)$ & $48.9(23.1)$ & $49.3(20.5)$ \\
& $\mathrm{n}=61$ & $\mathrm{n}=50$ & $\mathrm{n}=11$ \\
FEV1 \% pred & $39.4(19.7)$ & $65.9(8.5)$ & $69.3(6.3)$ \\
VC \% pred & $77.8(19.7)$ & $38.0(19.1)$ & $43.8(21.6)$ \\
FEV1/VC \% & $40.3(16.0)$ & $39.0(15.9)$ & $44.6(16.1)$ \\
$K C O \%$ pred & $89.3(36.0)$ & $85.2(34.4)$ & $101.6(39.2)$ \\
& $\mathrm{n}=56$ & $\mathrm{n}=42$ & $\mathrm{n}=14$ \\
$D \mathrm{~L}, \mathrm{CO} \%$ pred & $75.8(31.7)$ & $71.7(33.3)$ & $78.5(25.5)$ \\
& $\mathrm{n}=56$ & $\mathrm{n}=42$ & $\mathrm{n}=14$ \\
$P \mathrm{a}, \mathrm{O}_{2} \mathrm{kPa}$ & $8.98(1.59)$ & $8.42(9.79)$ & $5.65(10.88)$ \\
& $\mathrm{n}=27$ & $\mathrm{n}=23$ & $\mathrm{n}=4$ \\
$\mathrm{~Pa}_{\mathrm{a}, \mathrm{CO}} \mathrm{kPa}$ & $5.52(0.84)$ & $5.5(0.9)$ & $5.62(0.60)$ \\
& $\mathrm{n}=27$ & $\mathrm{n}=23$ & $\mathrm{n}=4$ \\
\hline
\end{tabular}

Data presented as mean(SD); $\mathrm{TR}+=$ visible tricuspid regurgitant jet; TR-=no visible tricuspid regurgitant jet; FEV1: forced expiratory volume in one second; VC: vital capacity; KCO: carbon monoxide transfer coefficient; $D$ L,CO: carbon monoxide diffusing capacity of the lung; $\mathrm{Pa}_{\mathrm{a}} \mathrm{O}_{2}$ : oxygen tension in arterial blood; $\mathrm{Pa}_{2} \mathrm{CO}_{2}$ : carbon dioxide tension in arterial blood. There are no significant differences between TR + and TR-groups (2-tailed unpaired t-tests).

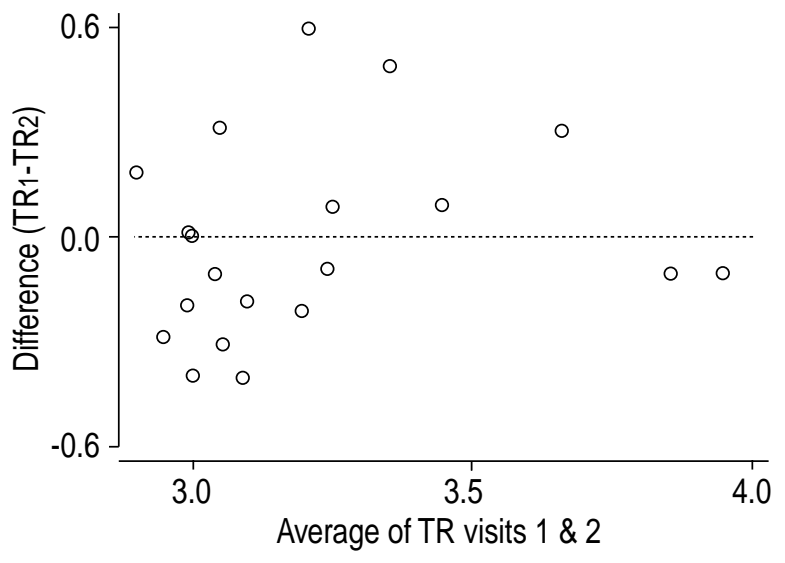

Fig. 1. - Bland-Altman plot of reproducibility of echocardiographic estimation of transtricuspid regurgitant jet velocity (TR) in 20 COPD patients. Mean(SD) difference $=-0.12(0.28) \mathrm{m} \cdot \mathrm{sec}^{-1}$, $95 \%$ limits of agreement $(-0.57,0.54)$. t-test: $t=-0.24, p=0.81)$.

reproducible with no evidence of bias (fig. 1). Importantly, no patient was reclassified as not having $\mathrm{PH}$ in the light of the second echocardiographic investigation.

In five normal subjects TTPG was confirmed to increase under acute hypoxic conditions (fig. 2). Mean(SD) TTPG was 20.7(2.4) $\mathrm{mmHg}$ during normoxia and $27.5(2.1)$ during hypoxia $(\mathrm{p}=0.0002)$.

Combining the data from all patients with COPD, there were statistically significant, but weak, inverse correlations of TTPG with $\%$ predicted FEV1 $(r=-0.26$, $\mathrm{p}=0.05$, fig. 3$), \%$ predicted $K \mathrm{CO}(\mathrm{r}=-0.31, \mathrm{p}=0.04$, fig. 4) and $\%$ predicted $D \mathrm{~L}, \mathrm{CO}(\mathrm{r}=-0.42, \mathrm{p}=0.006$, fig. 5). There were no correlations of TTPG with other measurements. Stepwise regression analysis revealed that a multivariable model (effect size $(95 \% \mathrm{CI})$ ) for predicting TTPG contains age $(0.013(0.002,0.025)$; $\mathrm{p}=0.02)$ and $\operatorname{KCO}(-0.004(-0.007,-0.001) ; \mathrm{p}=0.007)$.

\section{Discussion}

The present study demonstrates the utility of a state of the art continuous wave Doppler echocardiographic

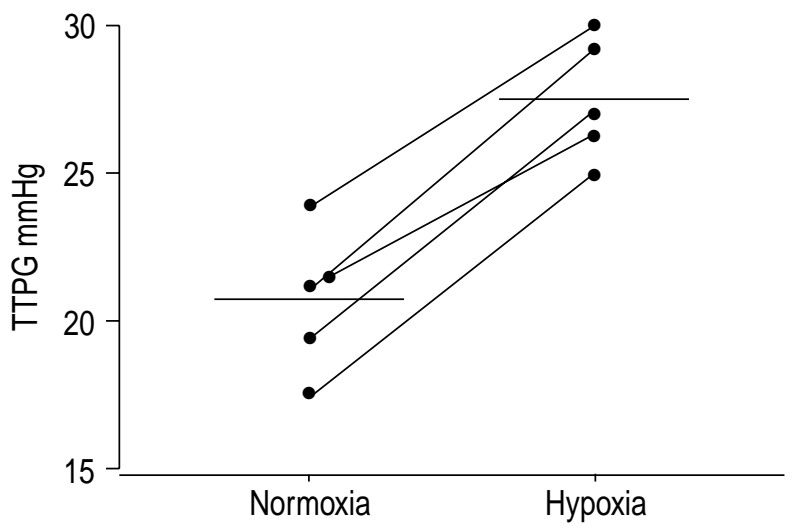

Fig. 2. - Increases in transtricuspid pressure gradient (TTPG) in five normal subjects breathing $10 \%$ oxygen (hypoxia) compared to room air (normoxia) $(\mathrm{p}=0.0002)$. Horizontal lines show mean values for each group. 


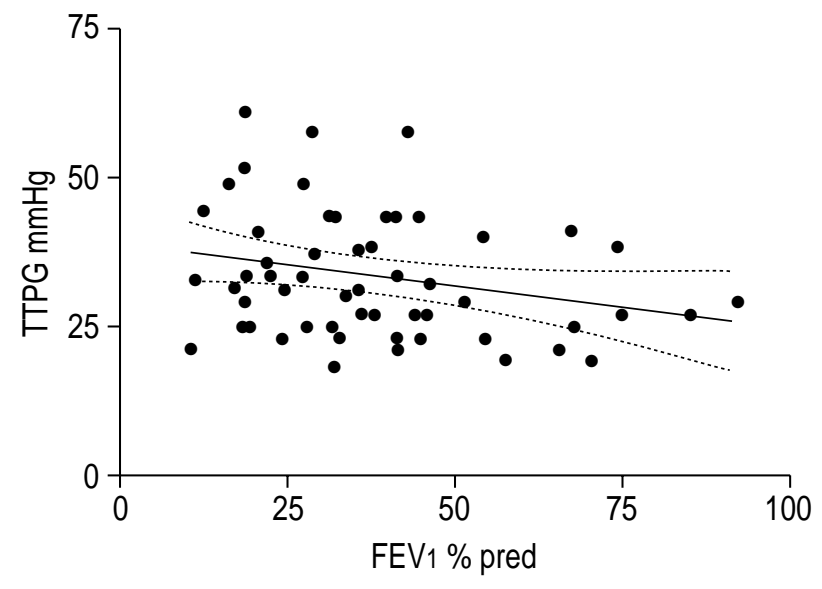

Fig. 3. - Correlation of transtricuspid pressure gradient (TTPG) with $\%$ pred forced expiratory volume in one second (FEV1) $(\mathrm{r}=-0.26, \mathrm{p}=0.05)$. Dashed lines show $95 \%$ confidence intervals for the line of regression.

technique to estimate TTPG in patients with COPD of varying severity. Echocardiographically-derived right ventricular systolic pressure (RVSP) is normally defined as the TTPG plus the right atrial pressure estimated from the elevation of the jugular venous pulse in $\mathrm{cm}$ with respect to the sternum. However, it is difficult to accurately measure the jugular venous pulse clinically. Yock et al. [14] showed that there is a poor correlation between clinically estimated and invasively measured right atrial pressure and that TTPG alone correlates just as closely with invasively measured RVSP as TTPG plus estimated right atrial pressure. It was therefore decided to avoid introducing potential measurement errors into the study by using TTPG alone as an index of RVSP.

Initial studies of evaluation of RVSP by catheterization and Doppler echocardiography suggested that the noninvasive method provides an accurate and widely applicable method, and that TTPG accurately reflects pulmonary arterial catheter measurements [14]. However, these studies were performed in selected patients with clinical signs of elevated right ventricular pressures. A subsequent large multicentre study concluded that Doppler echocardiography should be considered a useful screening technique but probably lacked accuracy [15]. However, the latter study reported that the TR signal was of sufficient quality for adequate measurement in only $30 \%$ of unselected COPD patients. In contrast, it has been found that more modern equipment allows the determination of transtricuspid pressures in over three-quarters of a group of COPD patients studied at a hospital outpatient clinic. Additionally, in a subgroup of patients with $\mathrm{PH}$ diagnosed echocardiographically the measurements were found to be adequately reproducible. As with the majority of physiological measurements, pulmonary arterial pressures would be expected to vary spontaneously [20, 21]. However, repeated measurement did not alter the diagnosis of pulmonary hypertension in the patients. It has previously been demonstrated that Doppler echocardiography is sufficiently sensitive to detect changes in pulmonary arterial

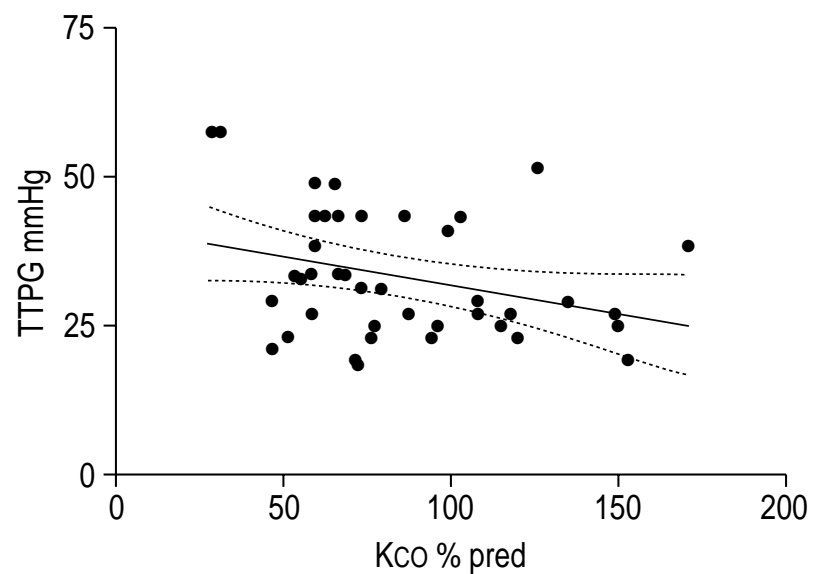

Fig. 4. - Correlation of transtricuspid pressure gradient (TTPG) with $\%$ pred KCO $(\mathrm{r}=-0.31, \mathrm{p}=0.04)$. Dashed lines show $95 \%$ confidence intervals for the line of regression.

pressure [22, 23]. Under conditions of acute hypoxia, pulmonary arterial pressure would be expected to rise as a consequence of hypoxic vasoconstriction in the pulmonary vascular bed [24] and, indeed, in a group of five normal individuals in the present study, continuous wave Doppler echocardiography was able to detect an increase in TTPG when the subjects breathed $10 \%$ oxygen for $10 \mathrm{~min}$. It is therefore suggested that the technique may be of value in following the course of pulmonary vascular disease and that it may also be of use in research in acute and chronic pharmacological and other interventions in PH secondary to COPD in which multiple repeated measurements are required.

The presented data show that $\mathrm{PH}$ is increasingly common with increasing severity of COPD and that there is a statistically significant correlation of TTPG with degree of emphysema as reflected by KCO measurement. Indeed, it has previously been suggested that loss of alveolar capillary bed surface area may contribute to the elevation of pulmonary arterial pressure associated with severe emphysema [25]. Although the authors have been unable to find other reports of correlations of TTPG with lung function

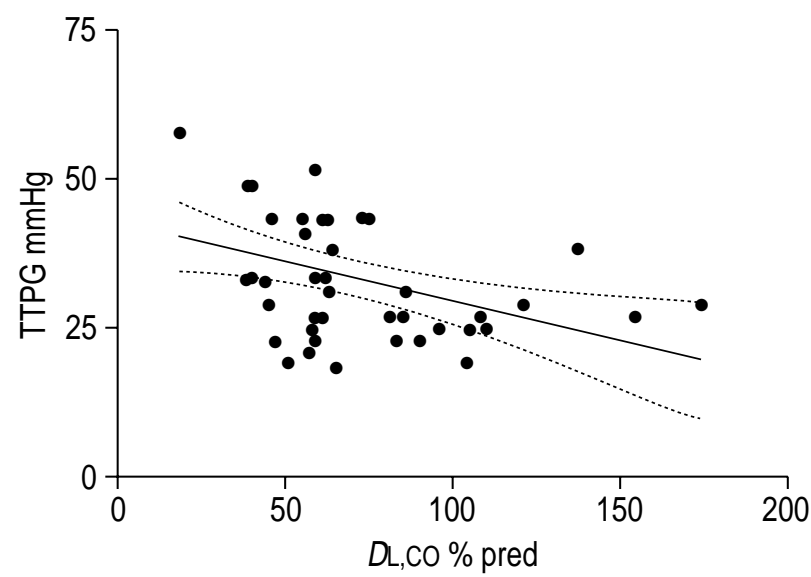

Fig. 5. - Correlation of transtricuspid pressure gradient (TTPG) with $\%$ pred $D$ L,CO $(\mathrm{r}=-0.42, \mathrm{p}=0.006)$. Dashed lines show $95 \%$ confidence intervals for the line of regression. 
tests in COPD, a previous study of 33 patients addressed whether pulmonary artery end diastolic pressure estimated echocardiographically correlated with pulmonary function indices and found a correlation with $\mathrm{KCO}$ but not $\mathrm{Pa}, \mathrm{O}_{2}$ [26]. A large multicentre study of 370 patients with COPD correlated invasively derived pulmonary arterial pressure with spirometry, but not gas transfer measurements, and obtained a correlation coefficient of -0.28 for FEV1 [5], which is remarkably similar to the value of -0.26 reported in the present study. This lends credence to the accuracy of echocardiographic estimation of pulmonary arterial pressures reported in the present paper. However, it should be noted that, even though statistically significant, the correlations of pulmonary arterial pressure with spirometric and gas transfer indices are fairly poor. Although a better predictor for $\mathrm{PH}$ than other measurements, the partial pressure of arterial oxygen has also previously been shown to correlate poorly with pulmonary arterial pressure measured invasively [5]. A statistically significant correlation between $\mathrm{Pa}_{2} \mathrm{O}_{2}$ and TTPG was not observed, but arterial blood gas measurements were only available in 27 patients, all of whom had severe disease.

Taken together, the present and previous data suggest that factors other than severity of COPD are contributors to the pathogenesis of $\mathrm{PH}$. These factors may include nocturnal desaturation, frequent exacerbations, changes in haematocrit and ventilatory response to hypoxia [7, 18]. Data is currently limited, but it is also possible that genetic influences are involved [27, 28], acting synergistically with the effects of chronic hypoxia and predisposing certain COPD patients to $\mathrm{PH}$.

Routine investigation of the presence of pulmonary arterial hypertension is not currently part of UK [16] or US [29] guidelines for the diagnosis and management of chronic obstructive pulmonary disease. Although patients generally undergo electrocardiography, it is insensitive in detecting right ventricular hypertrophy in chronic obstructive pulmonary disease [18]. Based on the present data showing the high prevalence of pulmonary arterial hypertension complicating severe chronic obstructive pulmonary disease, and the poor predictive power of lung function indices, a case could be made for screening all patients with severe chronic obstructive pulmonary disease for pulmonary arterial hypertension. This would contribute to the assessment of prognosis in these patients and assist in identifying individuals likely to suffer increased morbidity $[9,10]$ warranting close monitoring and intense treatment of their airways disease. Clearly, these speculations require further study.

Acknowledgements. The authors wish to thank C. Mordin and J. Curtis for their skilful technical assistance in performing this study.

\section{References}

1. Strachan DP. Epidemiology: a British perspective. In: Calverley $\mathrm{P}$, Pride NB, eds. Chronic obstructive pulmonary disease. London: Chapman \& Hall, 1995: pp. $48-67$.

2. Kozack LJ, Laurence L. National hospital discharge survey: annual summary, 1997. Vital and Health Statistics Series 13 no. 144. Hyattsville, Maryland: National Centre for Health Statistics, 1999.

3. Hoyert DL, Kochanek KD, Murphy SL. Deaths: final data for 1997. National vital statistics reports; Vol 47 no 19. Hyattsville, Maryland: National Centre for Health Statistics, 1999.

4. Weitzenblum E, Chaouat A, Oswald M. Pulmonary hypertension due to chronic hypoxic lung disease. In: Peacock AJ, Ed. Pulmonary Circulation. London: Chapman \& Hall, 1996: pp. 157-170.

5. Bishop JM, Csukas M. Combined use of non-invasive techniques to predict pulmonary arterial pressure in chronic respiratory disease. Thorax 1989; 44: 85-96.

6. Weitzenblum E, Sautegeau A, Ehrhart M, Mammosser M, Hirth C, Roegel E. Long-term course of pulmonary arterial pressure in chronic obstructive pulmonary disease. Am Rev Respir Dis 1984; 130: 993 - 998.

7. Weitzenblum E, Kessler R, Oswald M, Fraisse P. Medical treatment of pulmonary hypertension in chronic lung disease. Eur Respir J 1994; 7: 148 - 152.

8. Kessler R, Faller M, Fourgot G, Mennecier B, Weitzenblum E. Predictive factors of hospitalization for acute exacerbation in a series of 64 patients with chronic obstructive pulmonary disease. Am J Respir Crit Care Med 1999; 159: 158-164.

9. Weitzenblum E, Hirth C, Ducolone A, Mirhom R, Rasaholinjanahary J, Ehrhart M. Prognostic value of pulmonary artery pressure in chronic obstructive pulmonary disease. Thorax 1981; 36: $752-758$.

10. Cooper R, Ghali J, Simmons BE, Castaner A. Elevated pulmonary artery pressure: an independent predictor of mortality. Chest 1991; 99: 112-120.

11. Prichard JS. Pulmonary hypertension. In: Wetherall DJ, Ledingham JGG, Warrell DA, eds. Oxford textbook of medicine. 3rd ed. Oxford: Oxford University Press, 1996: 2505-2514.

12. Groves BM, Badesch DB. Cardiac catheterization of patients with pulmonary hypertension. In: Peacock AJ, Editor. Pulmonary circulation. London: Chapman \& Hall, 1996: 51-67.

13. Skjaerpe T, Hatle L. Diagnosis and assessment of tricuspid regurgitation with Doppler ultrasound. In: Rijsterborgh H, Editor. Echocardiology. The Hague: Martinus Nijhoff, 1981: 299-304.

14. Yock PG, Popp RL. Noninvasive estimation of right ventricular systolic pressure by Doppler ultrasound in patients with tricuspid regurgitation. Circulation 1984; 70: $657-662$.

15. Tramarin R, Torbicki A, Marchandise B, Laaban JP, Morpurgo M. Doppler echocardiographic evaluation of pulmonary artery pressure in chronic obstructive pulmonary disease. A European multicentre study. Eur Heart J 1991; 12: 103-111.

16. British Thoracic Society. BTS guidelines for the management of chronic obstructive pulmonary disease. Diagnosis and management of stable COPD. Thorax 1997; 52 (Suppl. 5): S7-S15.

17. European Respiratory Society. Standardized lung function testing. Eur Respir J 1993; 6 (Suppl. 16): $1-100$.

18. Macnee W. Pathophysiology of cor pulmonale in 
chronic obstructive pulmonary disease. Part one. $A m$ J Respir Crit Care Med 1994; 150: 833-852.

19. Bland JM, Altman DG. Statistical methods for assessing agreement between two methods of clinical measurement. Lancet 1986; i: 307-310.

20. Raeside DA, Chalmers G, Clelland J, Madhok R, Peacock AJ. Pulmonary artery pressure variation in patients with connective tissue disease: 24 hour ambulatory pulmonary artery pressure monitoring. Thorax 1998; 53: 857-862.

21. Rich S, Martinez J, Lam W, Rosen KM. Captopril as treatment for patients with pulmonary hypertension. Problem of variability in assessing chronic drug treatment. Br Heart $J$ 1982; 48: $272-277$.

22. Kiely DG, Cargill RI, Wheeldon NM, Coutie WJ, Lipworth BJ. Haemodynamic and endocrine effects of type I angiotensin II receptor blockade in patients with hypoxaemic cor pulmonale. Cardiovasc Res 1997; 33: 201-208.

23. Vachiery JL, McDonagh T, Moraine JJ, et al. Doppler assessment of hypoxic pulmonary vasoconstriction and susceptibility to high altitude pulmonary oedema. Thorax 1995; 50: $22-27$.

24. Morrell NW, Nijran KS, Biggs T, Seed WA. Changes in regional pulmonary blood flow during lobar bronchial occlusion in man. Clin Sci Colch 1994; 86: $639-644$.

25. Thurlbeck WM, Henderson JA, Fraser RG, Bates DV. Chronic obstructive lung disease. A comparison between clinical, roentgenologic, functional and morphologic criteria in chronic bronchitis, emphysema, asthma and bronchiectasis. Med 1970; 49: $81-145$.

26. Williams IP, Boyd MJ, Humberstone AM, Wilson AG, Millard FJC. Pulmonary arterial hypertension and emphysema. Br J Dis Chest 1984; 78: 211-216.

27. van Suylen RJ, Wouters EF, Pennings HJ, et al. The DD genotype of the angiotensin converting enzyme gene is negatively associated with right ventricular hypertrophy in male patients with chronic obstructive pulmonary disease. Am J Respir Crit Care Med 1999; 159: $1791-1795$.

28. Morrell NW, Sarybaev AS, Alikhan A, Mirrakhimov MM, Aldashev AA. ACE genotype and risk of high altitude pulmonary hypertension in Kyrghyz highlanders. Lancet 1999; 353: 814.

29. American Thoracic Society. Standards for the diagnosis and care of patients with chronic obstructive pulmonary disease. Am J Respir Crit Care Med 1995; 152 (Suppl.): S77-S120. 